Quim. Nova, Vol. 35, No. 3, 530-534, 2012

\title{
PERFORMANCE CHARACTERISTICS OF HIGH PERFORMANCE LIQUID CHROMATOGRAPHY, FIRST ORDER DERIVATIVE UV SPECTROPHOTOMETRY AND BIOASSAY FOR FLUCONAZOLE DETERMINATION IN CAPSULES
}

\author{
Josilene Chaves Ruela Corrêa, Camila Reichman e Hérida Regina Nunes Salgado* \\ Departamento de Fármacos e medicamentos, Faculdade de Ciências Farmacêuticas, Universidade Estadual Paulista, Rod. Araraquara- \\ Jaú, km 1, 14801-902 Araraquara - SP, Brasil \\ Cristina Duarte Vianna-Soares \\ Departamento de Produtos Farmacêuticos, Faculdade de Farmácia, Universidade Federal de Minas Gerais, Av. Pres. Antônio Carlos
} 6627, 31270-901 Belo Horizonte - MG, Brasil

Recebido em 1/6/11; aceito em 2/9/11; publicado na web em 7/10/11

\begin{abstract}
The bioassay, first order derivative UV spectrophotometry and chromatographic methods for assaying fluconazole capsules were compared. They have shown great advantages over the earlier published methods. Using the first order derivative, the UV spectrophotometry method does not suffer interference of excipients. Validation parameters such as linearity, precision, accuracy, limit of detection and limit of quantitation were determined. All methods were linear and reliable within acceptable limits for antibiotic pharmaceutical preparations being accurate, precise and reproducible. The application of each method as a routine analysis should be investigated considering cost, simplicity, equipment, solvents, speed, and application to large or small workloads.
\end{abstract}

Keywords: fluconazole; liquid chromatography; bioassay.

\section{INTRODUCTION}

Synthesized in 1982, as a first generation bis-triazole, fluconazole (Figure 1, CAS 86386-73-4), $\alpha$-(2,4-diflurophenyl)- $\alpha$-(1H-triazole1-methyl)-1H-1,2,4-triazole-1-ethanol, is a broad spectrum antifungal agent. It is used for the treatment of superficial, cutaneous and cutaneo-mucous infections caused by Candida species. It is a polar active pharmaceutical ingredient (API) and less lipophilic than other azoles (e.g. ketoconazole, itraconazole, miconazole). ${ }^{1}$ The presence of a halogen-phenyl group increases its antifungal activity and aqueous solubility, leading to higher bioavailability. ${ }^{2}$ In addition, its high metabolic stability was achieved by association of three structural features: the strength of the triazole ring to oxidative attack, the blockage of aromatic hydroxylation by the presence of two fluorine atoms and the steric hindrance of the hydroxyl site from a possible combination..$^{3-5}$<smiles>OC(Cn1cncn1)(Cn1cncn1)c1ccc(F)cc1F</smiles>

Figure 1. Fluconazol chemical structure (CAS 86386-73-4)

Fluconazole has three different $\mathrm{pKa}$ values equal to $11.01 \pm 0.29$; $2.94 \pm 0.10 ; 2.56 \pm 0.12 .{ }^{6}$ They correspond to alcohol and to ionizations of nitrogens. Thus, the aqueous fluconazole solubility increases in high and low $\mathrm{pH}$ values. Fluconazole $\log \mathrm{P}$ is 0.5 .

Although many methods using chromatographic techniques have been reported for the determination of fluconazole, as it was shown in a previous review, just few methods have been found in the literature for determination of fluconazole in pharmaceutical formulations using

*e-mail: salgadoh@fcfar.unesp.br derivative spectrophotometry and bioassay. ${ }^{7-9}$ These methods are used to evaluate fluconazole in capsules and most of chromatographic methods use relatively expansive solvent like acetronitrile, also they are not stability indicative methods. The advantages of the methods proposed over the others are the ability to access fluconazole capsules content using water and/or a solvent that does not suffer much price variability, as methanol; to be stability-indicating methods and independent of placebo interferences, in addition to access fluconazole capsules antifungal activity.

In this paper, the results of three different analytical methods were compared with respect to accuracy, precision and feasibility. They include high performance liquid chromatography, first derivative spectrophotometry and bioassay by means of microbiological evaluation. The study and comparison of analytical methods are important in order to help the analysts to choose the most applicable method for a given laboratory routine. ${ }^{10,11}$ The statistically validated proposed methods are suitable for routine determination of fluconazole in capsule pharmaceutical formulation. The aim of this work was to determine the performance characteristics of these methods considering simplicity, cost, time and sensitivity to quantify fluconazole, in addition to residues disposal.

\section{EXPERIMENTAL}

\section{Material and equipment}

Fluconazole chemical reference (assigned purity of 100\%) was purchased from Sigma Aldrich, raw material was kindly donated by EMS (Hortolândia, SP, Brazil). It was standardized against fluconazole chemical reference and thereafter, used as a working standard. Industrial generic product and compounding fluconazole capsules with a label claim $150 \mathrm{mg}$ of fluconazole were purchased from local pharmacies.

Chromatographic grade methanol (Tedia, Fairfield, OH, USA), sodium hydroxide, hydrochloric acid, and hydrogen peroxide (reagent grade, Merck Darmstadt, Germany) were used. Purified water 
(>18 $\mu \mathrm{S} / \mathrm{cm}$, Millipore, Billerica, MA, USA) was used to prepare mobile phase, sample and standard solutions. Prior to use, mobile phase systems were degassed in an ultrasonic bath for $30 \mathrm{~min}$. All solutions were filtered through a $0.45 \mu \mathrm{m}$ membrane filter before injection.

A UV-Visible spectrophotometer (HP 8453, Agilent Technologies, Santa Clara, CA, USA) with photodiode array (PDA) and HP ChemStation software was used for UV first derivative measurements. Liquid chromatograph equipped with a Waters 1525 binary pump, a manual injector (Breeze 7725i, Rheodyne), a Waters 2487 UV-VIS wavelength detector; and liquid chromatographic 290 modular system was used. Results were acquired and processed by internal software (Empower, Waters, Milford, MA, USA). Chromatographic analysis was conducted by using a RP C18 column (Symmetry, $5 \mu \mathrm{m}, 250 \mathrm{x}$ $4.6 \mathrm{~mm}$, Waters).

\section{Preparation of standard and sample solutions}

\section{Chromatographic method}

Fluconazole stock solution was prepared by dissolving $300 \mathrm{mg}$ of accurately weighed API in water in $100 \mathrm{~mL}$ volumetric flask. Fluconazole was solubilized with $5 \mathrm{~mL}$ of methanol and making up to volume with water. Further diluting different volumes: 2, 3, 4, 5, 7.5 and $10 \mathrm{~mL}$ in $25 \mathrm{~mL}$ volumetric flask with same solvent six final concentrations were obtained: 240, 360, 480, 600, 900 and $1200 \mu \mathrm{g} /$ $\mathrm{mL}$, respectively.

\section{UV method}

Fluconazole stock solution was prepared by dissolving $125 \mathrm{mg}$ of accurately weighted API in water in $100 \mathrm{~mL}$ volumetric flask and further diluting different volumes: 3, 4, 5, 6 and $7 \mathrm{~mL}$ in $25 \mathrm{~mL}$ volumetric flask with same solvent to give five final concentrations: $150,200,250,300$ and $350 \mu \mathrm{g} / \mathrm{mL}$, respectively.

\section{Bioassay}

Fluconazole stock solution was prepared by dissolving 6.24 $\mathrm{mg}$ of accurately weighted API in water in $25 \mathrm{~mL}$ volumetric flask and further diluting to volume with same solvent to give three final concentrations: 25,50 and $100 \mu \mathrm{g} / \mathrm{mL}$.

\section{Analytical conditions}

\section{UV method}

The spectrophotometric measure was performed using purified water as a blank. The spectrophotometer was programmed to generate the first-derivative scan between 200 and $400 \mathrm{~nm}$, using its standard speed to acquire spectra signals. Smoothing was not used. The quantitation involved measurement of amplitude of the first-derivative valley at $268 \mathrm{~nm}$.

\section{Chromatographic method}

Chromatographic analysis was performed in isocratic mode. Mobile phase consisted of methanol-water (60:40, v/v), being pumped at a flow rate of $1 \mathrm{~mL} / \mathrm{min}$. Injection volume was $20 \mu \mathrm{L}$ and detection wavelength was $261 \mathrm{~nm}$. The retention time of fluconazole was 3.7 min. All experiments were performed at room temperature and the total area of peak was used to quantify fluconazole.

\section{Biossay}

The microbiological assay (diffusion agar bioassay, cylinderplate) employed two agar layers (Sabouraud 2\% agar) with only the upper one inoculated with a standard suspension of Candida albicans ATCC $90028(25 \pm 2 \%$ transmittance at $580 \mathrm{~nm})$, at $2 \%$ concentration. After the agar solidified, six stainless steel cylinders size uniformed $(8 \times 6 \times 10 \mathrm{~mm})$ were placed on the surface of the inoculated medium in each Petri dish. Aliquots $(100 \mu \mathrm{L})$ of fluconazole working standard at concentrations of 25,50 and $100 \mu \mathrm{g} / \mathrm{mL}$, according to $3 \times 3$ assay, were added to three cylinders and $100 \mu \mathrm{L}$ of the samples solutions at the same concentrations were added to the other three cylinders.

After incubation $\left(25^{\circ} \mathrm{C}\right.$ for $\left.24 \pm 1 \mathrm{~h}\right)$, the antifungal activity was estimated based on the diameters of the microorganism growth inhibition zone $(\mathrm{mm})$ promoted by samples and by the reference substance. The inhibition zones were measured using an electronic digital caliper (Starret ${ }^{\circledR}$, USA). Fluconazole potency was determined by Hewitt's equation. ${ }^{12}$

\section{Method validation}

The methods were validated according to the International Conference on Harmonization (ICH) guidelines for validation of analytical methods. ${ }^{13}$

\section{Specificity}

Specificity was evaluated by comparison of absorbance spectra or chromatograms of samples containing possible interfering substances (excipient products used in capsules production) and samples containing fluconazole.

\section{Linearity}

The calibration curve was obtained at six concentration levels of fluconazole solutions for chromatographic method $(240-1200 \mu \mathrm{g} / \mathrm{mL})$ and five concentrations for first order derivative UV method (150-350 $\mu \mathrm{g} / \mathrm{mL}$ ). For bioassay, the calibration curve was obtained at three concentration levels $(25-100 \mu \mathrm{g} / \mathrm{mL})$. The linearity was evaluated by the least square regression method with triplicate determinations at each concentration level.

\section{Precision}

Precision was assessed at different levels: repeatability, by testing three curves constructed with five different standard solution concentrations, in the same day; and intermediate, by analyzing three different standard solution concentrations high, intermediate and low, in a different day, with two days interval between repeatability and intermediate. The precision of the assay method was evaluated by carrying out by calculating the \%R.S.D. of assay.

\section{Accuracy}

The recoveries were determined by adding known amounts of fluconazole reference substances to placebo at the beginning of the process. The levels of API addition were 40, 60, 80, 100, 150 and $200 \%$ of the working concentration for the chromatographic method; $60,80,100,120$ and $140 \%$ of working concentration for the spectrophotometric method; 25,50 and $100 \mu \mathrm{g} / \mathrm{mL}$ of API for the bioassay.

\section{Limits of detection (LOD) and quantitation (LOQ)}

The LOD and LOQ of fluconazole by the proposed methods were determined using calibration standards. LOD and LOQ were calculated as 3 and $10 \sigma / S$, respectively, where $S$ is the slope of the calibration curve and $\sigma$ is the standard deviation of $y$-intercept of regression equation. ${ }^{13}$

\section{Robustness}

Robustness was evaluated by Youden and Steiner method. ${ }^{14}$ By this method seven different parameters could be evaluated by eight analytical runs employing factorial combination. 


\section{RESULTS AND DISCUSSION}

\section{Chromatographic method}

The development of the chromatographic method for the determination of APIs has received considerable attention in recent years because of their importance in routine quality control analysis. ${ }^{10}$

A comparison of three analytical methods was performed for antibiotic fluconazole, to serve as tool option for diverse laboratories. A reversed-phase chromatographic method was proposed because it as a suitable method for the estimation of fluconazole in pharmaceutical dosage form. The chromatographic conditions were adjusted in order to provide a satisfactory performance and feasibility with a relatively low cost of solvents used in the preparation of mobile phase. ${ }^{10}$ Elution parameters evaluated were peak asymmetry (tailing factor, T), number of theoretical plates $(\mathrm{N})$ and retention factor $\left(\mathrm{k}^{\prime}\right)$. The superposed chromatograms of fluconazole standard solutions, sample solutions and placebo are shown in Figure 2. Results obtained with endcapped octadecilsilane column (C18) and mixture of methanol and water (60:40, $\mathrm{v} / \mathrm{v})$ as mobile phase were satisfactory and can be seen in Table 1.

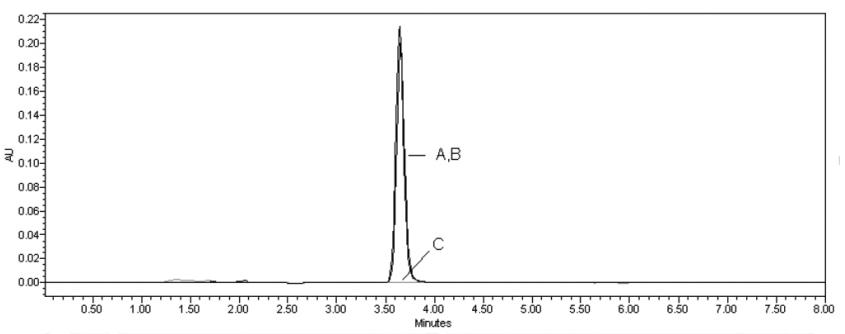

Figure 2. Overlay chromatograms for fluconazole RS (A), fluconazole capsules (B) and its placebo $(C)$. Fluconazole dilution equivalent $(600 \mu \mathrm{g} / \mathrm{mL})$ chromatogram eluted from Waters $C 18$ column $(250 \times 4 \mathrm{~mm}, 5 \mu \mathrm{m})$ with mobile phase methanol-water (60:40), $1 \mathrm{~mL} / \mathrm{min}$ flow rate, and $\lambda 261 \mathrm{~nm}$

Table 1. Chromatographic parameters and the acceptance criteria for fluconazole determination by developed LC method ${ }^{22}$

\begin{tabular}{lcc}
\hline Chromatographic parameters & Results & Acceptance criteria \\
\hline $\mathrm{t}_{\mathrm{R}}$ (retention time, min) & 3.7 & - \\
$\mathrm{T}_{0}$ (column dead time, min) & 1.2 & - \\
$\mathrm{k}^{\prime}$ (retention factor) & 2.08 & $2<\mathrm{k}^{\prime}<10$ \\
$\mathrm{~T}$ (tailing factor) & 1.33 & $0.8-1.5$ \\
$\mathrm{~N}$ (column efficiency) & 2196 & $\mathrm{~N}>2000$ \\
\hline
\end{tabular}

The retention time observed (3.7 min) allows a rapid determination of the API, what is desirable for a routine analysis. The calibration curves for fluconazole were constructed by plotting concentration versus peak area and showed good linearity over the concentration range from 240 to $1200 \mu \mathrm{g} / \mathrm{mL}\left(\mathrm{r}^{2}=0.9997\right)$. The method limits of detection and quantification were 6.72 and $22.41 \mu \mathrm{g} / \mathrm{mL}$, respectively (Table 2 ). The validity of the assay was verified by means of the ANOVA. According to ANOVA there is linear regression (Fcalculated $>/$ Fcritical; $\mathrm{P}=0.05$ ) and there is no deviation from linearity (Fcalculated $</$ Fcritical; $\mathrm{P}=0.05$ ). The precision of the method was determined by repeatability (intra-day) and intermediate precision (inter-day) and was expressed as R.S.D. (\%) of a series of measurements. The result obtained shows R.S.D. $0.82 \%$, indicating good intra-day precision and inter-day variability shows a mean R.S.D. $1.96 \%$ (Table 2). The accuracy of the method was determined and the mean recovery was found to be $101.06 \%$ (Table 3) providing agreement between the true value and the value found.
Table 2. Validation parameters for chromatographic, bioassay and the firstorder derivative UV methods of fluconazole capsules

\begin{tabular}{|c|c|c|c|}
\hline Parameters & UV method & $\begin{array}{c}\text { Chromatographic } \\
\text { method }\end{array}$ & Bioassay \\
\hline $\begin{array}{l}\text { Useful concentration, } \\
\mu \mathrm{g} / \mathrm{mL}\end{array}$ & 250 & 600 & $25 ; 50$ and 100 \\
\hline Analytical curve & $0.446 \mathrm{X}+5.3 \times 10^{-4}$ & $5.334 \mathrm{X}+2.084$ & $11.76 \mathrm{X}-1.358$ \\
\hline $\begin{array}{l}\text { Determination } \\
\text { coefficient }\left(\mathrm{r}^{2}\right)\end{array}$ & 0.9997 & 0.9997 & 0.9984 \\
\hline $\begin{array}{l}\text { R.S.D. of } \\
\text { repeatability }(\%)\end{array}$ & 0.65 & 0.82 & 4.34 \\
\hline $\begin{array}{l}\text { R.S.D. intermediate } \\
\text { precision }(\%)\end{array}$ & 0.75 & 1.96 & 6.15 \\
\hline Accuracy (\%) & 100.22 & 101.06 & 97.30 \\
\hline RSD of accuracy (\%) & 0.65 & 0.69 & 5.98 \\
\hline $\begin{array}{l}\text { Detection limit }{ }^{\mathrm{a}} \text {, } \\
\mu \mathrm{g} / \mathrm{mL}\end{array}$ & 1.87 & 6.72 & 0.59 \\
\hline $\begin{array}{l}\text { Quantitation limit }{ }^{\mathrm{b}} \text {, } \\
\mu \mathrm{g} / \mathrm{mL}\end{array}$ & 6.25 & 22.41 & 1.98 \\
\hline
\end{tabular}

a $3 \sigma / \mathrm{S} ;{ }^{\mathrm{b}} 10 \sigma / \mathrm{S}$.

Table 3. Recovery data of standard solutions added to the placebo analyzed by using the proposed chromatographic, bioassay and first derivative UVspectrometry method

\begin{tabular}{lccc}
\hline Method & $\begin{array}{c}\text { Added amount } \\
(\mu \mathrm{g} / \mathrm{mL})\end{array}$ & $\begin{array}{c}\text { Found }^{\mathrm{a}} \text { amount } \\
(\mu \mathrm{g} / \mathrm{mL})\end{array}$ & $\begin{array}{c}\text { Recovery }^{\mathrm{a}} \\
(\%) \pm \text { R.S.D. }\end{array}$ \\
\hline Chromatographic & 240.00 & 242.33 & $101.0 \pm 0.5$ \\
method & 360.00 & 360.86 & $100.2 \pm 0.4$ \\
& 480.00 & 487.01 & $101.5 \pm 0.3$ \\
& 600.00 & 610.14 & $101.7 \pm 0.3$ \\
& 900.00 & 907.74 & $100.9 \pm 0.7$ \\
& 1200.00 & 1216.44 & $101.4 \pm 0.4$ \\
UV spectrophotometry & 150.00 & 149.26 & $99.5 \pm 0.4$ \\
& 200.00 & 199.78 & $99.9 \pm 0.4$ \\
& 250.00 & 251.05 & $100.4 \pm 0.7$ \\
& 300.00 & 302.37 & $100.8 \pm 0.6$ \\
& 350.00 & 351.78 & $100.5 \pm 0.2$ \\
Bioassay & 25.00 & 24.24 & $97.0 \pm 6.7$ \\
& 50.00 & 48.48 & $97.0 \pm 6.4$ \\
& 100.00 & 97.98 & $98.0 \pm 5.2$ \\
\hline
\end{tabular}

${ }^{\mathrm{a}}$ Mean of three replicates

\section{Robustness}

Robustness testing is useful in order to prove that typical variations to the method are negligible in the procedure outcome. It is usually studied by deliberately changing critical parameters and monitor possible alterations. A method is robust when these alterations produce no significant changes in its results.

The robustness test by Youden and Steiner method can evaluate the interference of low and deliberated changes in seven parameters on the fluconazole content. ${ }^{14}$ Tables 4 and 5 show the factorial combination of analytical parameters and each parameter variation evaluated.

To evaluate the effect of each variation on the fluconazole assay the following equation was used. ${ }^{15}$

$A=\frac{x+y+w+z}{4}-\frac{s+t+u+v}{4} \quad$ (Equation to parameter A, a) 
Table 4. Factorial combination to Youden \& Steiner test ${ }^{14}$

\begin{tabular}{ccccccccc}
\hline & \multicolumn{7}{c}{ Factorial combination } \\
\cline { 2 - 9 } Parameter & 1 & 2 & 3 & 4 & 5 & 6 & 7 & 8 \\
\hline B,b & A & A & A & A & a & a & a & a \\
C,c & B & B & b & b & B & B & B & b \\
D,d & D & c & C & c & C & C & C & c \\
E,e & E & e & E & e & E & E & E & E \\
F,f & F & $\mathrm{f}$ & $\mathrm{f}$ & F & F & F & F & F \\
G,g & G & g & g & G & G & G & G & g \\
Results & $S$ & $t$ & $u$ & $v$ & $x$ & $y$ & $W$ & $z$ \\
\hline
\end{tabular}

Table 5. Analytical parameters and its variations

\begin{tabular}{clc}
\hline Parameters & & Variations \\
\hline \multirow{2}{*}{ A } & Chromatographic column & A: Waters ${ }^{\circledR a}$ \\
& Wavelength & a: Agilent ${ }^{\circledR a}$ \\
B & Flow rate & B: $261 \mathrm{~nm}$ \\
& & b: $266 \mathrm{~nm}$ \\
C & Mobile phase & C: $1.0 \mathrm{~mL} / \mathrm{min}$ \\
& & c: $0.8 \mathrm{~mL} / \mathrm{min}$ \\
D & Injection volume & D: $60: 40^{\mathrm{b}}$ \\
& & d: $57: 43^{\mathrm{b}}$ \\
E & Oven temperature & E: $20 \mu \mathrm{L}$ \\
& & E: $15 \mu \mathrm{L}$ \\
F & Agitation time & F: $20{ }^{\circ} \mathrm{C}$ \\
& & f: $25^{\circ} \mathrm{C}$ \\
G & & G: $30 \mathrm{~min}$ \\
\end{tabular}

${ }^{\mathrm{a}} \mathrm{C} 18,250$ x $4.6 \mathrm{~mm}, 5 \mu \mathrm{m} ;{ }^{\mathrm{b}}$ methanol:water.

The major effect on the fluconazole content was obtained with parameter G, g (4.74\%). Therefore, agitation time should be rigorously obeyed. The results to others parameters show that few and unintentional changes do not affect the test.

\section{First-derivative UV method}

A greater selectivity of the UV derivative method is one of the most important characteristics compared to UV zero order (normal) spectrophotometry. In fluconazole tested capsules, zero order spectrophotometric method suffers high placebo interference, circa of $4 \%$. According to USP 32 interferences should not exceed 2\%. Using a UV first order derivative method interferences were reduced to $0.1 \%$. Figure 3 shows the UV first order derivative absorption spectrum of fluconazole in aqueous solution in the wavelength range $200-400 \mathrm{~nm}$.

The placebo interference was evaluated from first to forth derivative order. In the UV first order derivative there is an intense, better

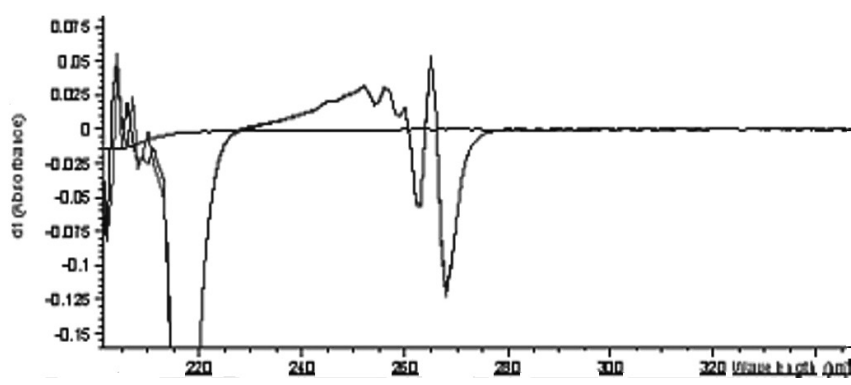

Figure 3. Fluconazole first order derivative UV spectrum characterized valley at $\lambda 268 \mathrm{~nm}$, which shows no interferences. This wavelength was used for all measurements. The increased selectivity, observed in the derivative spectroscopy, is based on the relationship between the amplitude of the derivative absorbance and the wavelength. It is inversely proportional to the bandwidth of the ordinary spectrum. The order of the derivative was carefully selected, since usually there is an increase in noise level with increasing order of derivation. ${ }^{16,17}$

The proposed UV derivative method allows a rapid and economical quantitation of fluconazole in capsules without any timeconsuming sample preparation. Moreover, the spectrophotometric methods involve simpler and cheaper instrumentation compared to other instrumental techniques, as for instance, chromatographic methods. ${ }^{10}$

For accurate analysis, the range of calibration curves was constructed from $150-350 \mu \mathrm{g} / \mathrm{mL}$. According to Beer's law, an effort to work with a concentration response in the mid range of the usual linear interval ( 0.2 to 0.8 absorbance units, AU) was made. Thus, the selected working concentration was $250 \mu \mathrm{g} / \mathrm{mL}$, which showed an absorbance response equal to $0.5 \mathrm{AU}$. The results showed good linearity over this concentration range with a determination coefficient of 0.9997 (Table 2). The method limits of detection and quantification were 1.87 and $6.25 \mu \mathrm{g} / \mathrm{mL}$, respectively. According to ANOVA there is linear regression (Fcalculated $>$ Fcritical; $\mathrm{P}=0.05$ ) and there is no deviation from linearity (Fcalculated $<$ Fcritical; $\mathrm{P}=0.05$ ). The precision of the method was determined by repeatability (intra-day) and intermediate precision (inter-day) and was expressed as R.S.D. (\%) of a series of measurements. The result obtained shows R.S.D. $0.65 \%$ for intra-assay precision and a mean R.S.D. $0.75 \%$ for interassay variability indicating satisfactory results (Table 2 ). The accuracy of the method was determined and the mean recovery, found to be $100.22 \%$ (Table 3), is indicative of a good agreement between the true value and the value found.

\section{Bioassay}

In this work experimental $3 \times 3$ design using three dose levels for each standard and sample were used following the procedure described in Brazilian, European and British Pharmacopeias. ${ }^{18-20}$

The calculation procedure normally assumes a direct relationship between the observed zone diameter and logarithm of applied dose. ${ }^{10}$ The calibration curve for fluconazole was constructed by plotting log of concentrations $(\mu \mathrm{g} / \mathrm{mL})$ versus zone diameter $(\mathrm{mm})$ and showed good linearity from 25 to $100 \mu \mathrm{g} / \mathrm{mL}$ range. The coefficient of determination was $r^{2}=0.9984$. According to Brazilian, European, and British Pharmacopoeias, ${ }^{18-20}$ if a parallel-line model is chosen, the two log dose-response lines of the preparation to be examined and the reference preparation must be parallel and they must be linear over the range of doses used in the calculation. ${ }^{10}$ These conditions must be verified by validity tests for a given probability, usually $\mathrm{P}=$ 0.05 . The assays were validated by means of the analysis of variance, as described in these official codes. ${ }^{10}$ There were no deviation from parallelism and linearity with results obtained here $(P=0.05)$. The precision of the method was determined by repeatability (intra-day) and intermediate precision (inter-day) and was expressed as R.S.D. (\%) of a series of measurement. The results obtained shows R.S.D. $4.34 \%$ (Table 2). Inter-day variability was calculated from assays on 3 days and shows a mean R.S.D. $6.15 \%$ (Table 2). The mean recovery found was equal to $97.30 \%$ (Table 3 ). This method shows good agreement between the true value and the value found.

Although the bioassays have a greater variability, the results demonstrate that the proposed method is very useful for fluconazole activity determination in pharmaceutical dosage forms. In addition, 
the bioassay remains, according to U.S. Pharmacopeia, ${ }^{21}$ as an applicable method to clear any doubts regarding the quantitation of antimicrobial APIs.

\section{CONCLUSION}

Three methods of analysis for fluconazole in both raw material and capsules have been described and compared regarding precision, accuracy, repeatability, cost and ease of handling. All methods showed to be specific, precise, accurate and linear in the concentration ranges tested.

Obviously, these methods have intrinsical differences. The chromatographic method is the most expensive method. It requires special equipment and expensive solvents. The spectrophotometric analysis also requires special equipment, however, the cost of a spectrophotometer is less than a liquid chromatograph system. The bioassay is, clearly, the least expensive method presented because it requires no special equipment. ${ }^{10}$

The ease of handling, as measured by technician time required for performance, is another determination factor to select a method for laboratory routine. ${ }^{10}$ Bioassay is limited by incubation time, 24 h. Both spectrophotometic and chromatographic methods provide results in $2 \mathrm{~h}$. The first order derivative UV spectrophotometric method is highly selective and sensitive. HPLC as a separation technique can show interfering peaks and to be a stability indicated method, meanwhile the bioassay shows the antifungal activity and remains, according to U.S. Pharmacopeia, ${ }^{21}$ as applicable method to clear any doubts regarding the determination of antimicrobial APIs.

Our study leads to conclude that the application of each method as a routine analysis should be investigated considering cost, simplicity, equipment, solvents, speed, and application to large or small workloads.

\section{ACKNOWLEDGMENTS}

The authors wish to thank the pharmaceutical company EMS (Brazil) for the supply of the raw material and thank the Fapesp, $\mathrm{CNPq}$ and PADC - UNESP to financial support.

\section{REFERENCES}

1. Grant, S. M.; Clissold, S. P.; Drugs 1990, 39, 877.

2. Brammer, K. W.; Farrow, P. R.; Faulkner, J. K.; Rev. Infect. Dis. 1990 , 12, S318

3. Dash, A. K.; Elmquist, W. F.; Fluconazol. Analytical profiles of drug substances and excipients; Academic Press: San Diego, 2001.

4. O'Neil, M. J.; The Merck Index - An Encyclopedia of Chemicals, Drugs, and Biologicals, $14^{\text {th }}$ ed., 2006.

5. Pereira, D. G.; Quim. Nova 2007, 30, 171.

6. ACD/pKa DB; Program for Advanced Chemistry Development Inc., Copyrigh $^{\odot} 1994-2002$.

7. Correa, J. C. R.; Salgado, H. R. N.; Crit. Rev. Anal. Chem. 2011, 41, 124.

8. Göger, N. G.; Aboul-Enein, H. Y.; Anal. Lett. 2001, 34, 2089.

9. Aboul-Enein, H. Y.; Göger, N. G.; Türkalp, A.; Anal. Lett. 2002, 35, 1193.

10. Lopes, C. C. G. O.; Salgado, H. R. N.; Quim. Nova 2008, 31, 1831.

11. Pektaş G.; Dinç E.; Baleanu, D.; Quim. Nova 2009, 32, 1416.

12. Hewitt, W.; Microbiological assay, Academic Press: New York, 1977.

13. ICH; Validation of Analytical Procedures: Text and Methodology, Harmonized Tripartite Guideline Q2 (R1), 2005.

14. Youden, W. J.; Steiner, E. H.; Statistical manual of AOAC-Association of Official Analytical Chemistry, AOAC: Washington, 1975.

15. César, I. C.; Pianetti, G. A.; Braz. J. Pharm. Sci. 2009, 45, 235.

16. Rocha, F. R. P.; Teixeira, L. S. G.; Quim. Nova 2004, 27, 807.

17. Sanchez-Rojas, F.; Ojeda, C. B.; Pavon, J. M. C.; Talanta 1988, 35, 753.

18. Farmacopéia Brasileira, $5^{\text {a }}$ ed., Editora Instituto Oswaldo Cruz: Rio de Janeiro, 2010.

19. European Pharmacopoeia, $7^{\text {th }}$ ed., European Directorate for the Quality of Medicines and Health Care, Council of Europe: Strasbourg, 2011.

20. British Pharmacopoeia, Her Majesty's Stationery Office: London, 2011.

21. United States Pharmacopoeia, $34^{\text {th }}$ ed., United States Pharmacopeial Convention: Rockville, 2011.

22. Harris, D. C.; Análise Química Quantitativa, 6a ed., LTC - Livros Técnicos e Científicos: Rio de Janeiro, 2005. 